\title{
Lactic Acidosis in a Man with Diabetes: Is Metformin the Culprit?
}

Harsha Anuruddhika Dissanayake ${ }^{1^{*}}$, Eranga S Wijewickrama ${ }^{2}$ and Prasad Katulanda ${ }^{1,2}$

${ }^{1}$ Diabetes Research Unit, Faculty of Medicine, University of Colombo, Sri Lanka

${ }^{2}$ Department of Clinical Medicine, Faculty of Medicine, University of Colombo, Sri Lanka

*Corresponding author: Harsha Anuruddhika Dissanayake, Diabetes Research Unit, Faculty of Medicine, University of Colombo, Sri Lanka, Tel: +94-714219893; Email: dissanayakeha@gmail.com

Received date: January 03, 2018; Accepted date: January 12, 2018; Published date: January 17, 2018

Copyright: (c) 2018 Dissanayake HA, et al. This is an open-access article distributed under the terms of the Creative Commons Attribution License, which permits unrestricted use, distribution, and reproduction in any medium, provided the original author and source are credited.

\begin{abstract}
Background: Lactic acidosis is a rare but serious adverse effect of metformin, particularly when used in high doses in patient with other risk factors. We report a case of metformin associated lactic acidosis that improved with hemodialysis.

Case presentation: Seventy-year-old male with diabetes and stage IV chronic kidney disease presented with vomiting and was found to have lactic acidosis with lactate of $8 \mathrm{mmol} / \mathrm{L}$ while being on metformin $1 \mathrm{~g}$ thrice daily. He was successfully managed with haemodialysis and supportive care.

Conclusion: This case illustrates the importance of judicious drug prescription in patients with multiple comorbidities; need to consider metformin induced lactic acidosis in appropriate settings and importance of active management with haemodialysis. Recommendations on prevention and options for treatment are also be discussed.
\end{abstract}

Keywords: Metformin; Lactic acidosis; Chronic kidney disease; Diabetes

\section{Background}

Metformin is the first line agent in the treatment of type 2 diabetes mellitus [1]. It is also used in management of metabolic syndrome and polycystic ovary syndrome [2]. Metformin acts by reducing hepatic glucose production and increasing insulin sensitivity of peripheral tissues [3]. Metformin is eliminated unchanged by the kidneys [4]. It has a half-life of 2-8 hours, but is longer in renal impairment [5].

Metformin is very effective in glycaemic control, has favourable cardiovascular outcomes, and improves lipids and fatty liver disease [6]. It also has a favourable safety profile with minimal hypoglycaemia and being weight neutral or in some patients can cause weight loss [7]. Gastrointestinal disturbances are the commonest side effects. In overdose it is known to cause hypotension, hypothermia and altered consciousness as well as hypoglycaemia which is exacerbated by cotreatment with ACE inhibitor [8].

Lactic acidosis is a rare complication of metformin therapy [3]. Its incidence in different case series have ranged from 3 to 47 per 100000 patient years [9]. However a recent review of prospective and observational studies concluded no increased risk over other oral hypoglycaemic agents [10]. Phenformin, the other biguanide that was in use, was withdrawn from the market in late 1970's due to high rate of phenformin induced lactic acidosis [11,12]. However incidence of metformin associated lactic acidosis remains much less and virtually unseen even in some settings where large numbers of diabetic patients are managed over many years.

Metformin induced lactic acidosis (MILA) refers to lactic acidosis in a patient on metformin in the absence of other recognized risk factors or causes for lactic acidosis whereas metformin associated lactic acidosis (MALA) is the term to describe when such risk factors also coexist [8].

We describe a patient who developed lactic acidosis while on high dose metformin.

\section{Case Presentation}

A 70-year-old male presented with nausea, vomiting and malaise progressively worsening over 3 days and reduced urine output on the third day. He denied fever, dysuria, cough, dyspnea, chest pain, headache or diarrhea. He had diabetes mellitus for 20 years, hypertension and stable angina for 3 years and had been recently detected to have chronic kidney disease. He had been on metformin 1 g thrice daily for more than 5 years along with gliclazide, enalapril, atorvastatin and low dose aspirin. The same regimen had been continued despite of having a recent (one month before admission) serum creatinine level of $2.4 \mathrm{mg} / \mathrm{dL}$ due to delays in follow up.

On admission he was ill, drowsy, dehydrated and had a pulse rate 104 beats per minute, blood pressure of $100 / 60 \mathrm{mmHg}$, respiratory rate of 32 per minute, temperature of $98.8^{\circ} \mathrm{F}$ and $\mathrm{SpO}_{2}$ of $98 \%$ in room air. System examination did not reveal any abnormalities.

Investigations showed normochromic normocytic anaemia (haemoglobin $10.2 \mathrm{~g} / \mathrm{dL}$ ), normal total leucocyte count and differential, CRP of $10 \mathrm{mg} / \mathrm{L}$ (normal $<6 \mathrm{mg} / \mathrm{L}$ ) and normal random capillary blood glucose $(145 \mathrm{mg} / \mathrm{dL})$. Blood biochemistry detected hyponatraemia $(129 \mathrm{mmol} / \mathrm{L})$, hypokalaemia $(3.45 \mathrm{mmol} / \mathrm{L})$ and elevated serum creatinine $(5.4 \mathrm{mg} / \mathrm{dL})$. Liver biochemistries were normal.

Urinalysis detected 10-15 pus cells per high power field in centrifuged sample. Urine and blood cultures did not isolate any microorganisms. Abdominal ultrasonography only showed evidence of 
chronic renal parenchymal disease. Twelve lead electrocardiogram and echocardiogram were normal.

Arterial blood gas analysis showed severe metabolic acidosis with hyperlactataemia $\left(\mathrm{pH} 7.17, \mathrm{PCO}_{2} 11.6 \mathrm{mmHg}, \mathrm{PO}_{2} 123.0 \mathrm{mmHg}\right.$, $\mathrm{HCO}_{3}{ }^{-} 5.4 \mathrm{mmol} / \mathrm{L}$, base deficit $23.4 \mathrm{mmol} / \mathrm{L}$ and serum lactate 8 $\mathrm{mmol} / \mathrm{L}(0.5-2.2)$ suggesting the diagnosis of severe lactic acidosis.

$\mathrm{He}$ was successfully resuscitated with crystalloid volume replacement. Metformin was withheld and empiric antibiotics were commenced for a presumed urinary tract infection. Despite these measures acidosis continued to worsen and he required four sessions of haemodialysis before his acidosis got corrected and lactate returned to normal.

He was commenced on biphasic insulin in place of metformin. During a follow up 4 weeks later his serum creatinine was stable at 2.6 $\mathrm{mg} / \mathrm{dL}$ without further dialysis, and glycaemic control was satisfactory (HbAlc 7.6\%, fasting plasma glucose $133 \mathrm{mg} / \mathrm{dL}$ ). He was administering insulin by himself with the support of family members and had no major hypoglycaemic events.

\section{Discussion}

Severe metabolic acidosis in our patient was most likely to be a result of hyperlactataemia and acute kidney injury. High dose metformin in a background of renal dysfunction in the absence of other factors that would cause systemic hypoxia (such as sepsis or cardiac failure) makes metformin associated lactic acidosis (MALA) the most likely diagnosis. Although severe sepsis, hypotension, severe hypoxaemia, cardiac or hepatic failure can also cause lactic acidosis, absence of fever, near normal inflammatory markers, negative cultures, normal blood pressure and oxygen saturation, normal cardiac and liver function tests make those alternatives less likely.

Principle mechanism of MALA is thought to be inhibition of mitochondrial function in hepatocytes resulting in inhibition of aerobic oxidation and accumulation of lactate [13]. This explains why haemodiafiltration is effective in treatment as it removes metformin and lactate to negate acidosis. Therefore despite very low $\mathrm{pH}$ and high lactate, survival is better compared to lactic acidosis of other aetiologies. It is also postulated that metformin causes peripheral vasodilation by activating endothelial nitric oxide synthase (eNOS) [14] and in patients with sepsis, this may cause worsening of septic shock [8] and therefore lactic acidosis. eNOS activation as well as myocardial dysfunction secondary to severe acidosis might have contributed to fall in blood pressure in our patient.

Recommended maximum daily dose of metformin is 2 grams, in the absence of other co-morbidities [15]. Although it is accepted that metformin should be used cautiously in moderate renal impairment or be avoided altogether in advanced renal impairment, recommendations vary on exact cut offs [16]. For instance, Kidney Disease Outcomes Quality Initiative guidelines recommend metformin to be contraindicated if serum creatinine level exceeds $1.4 \mathrm{mg} / \mathrm{dL}$ in women or $1.5 \mathrm{mg} / \mathrm{dL}$ in men [17]. A consensus statement of American Diabetes association and European Association for the Study of Diabetes states metformin is safe (at a reduced dose) as long as eGFR is greater than $30 \mathrm{~mL} / \mathrm{min} / 1.73 \mathrm{~m}^{2}$ [18]. This is consistent with the recommendations of Canadian Diabetes Association [19] and Australian Diabetes Society, although these two authorities differ slightly in their cut offs recommending caution; eGFR $30-45 \mathrm{~mL} / \mathrm{min} /$ $1.73 \mathrm{~m}^{2}$ in the former and $30-60 \mathrm{~mL} / \mathrm{min} / 1.73 \mathrm{~m}^{2}$ in the latter.
Similarly, National Institute for Health and Clinical Excellence recommends caution if serum creatinine exceeds $1.5 \mathrm{mg} / \mathrm{dL}$ or eGFR falls below $45 \mathrm{~mL} / \mathrm{min} / 1.73 \mathrm{~m}^{2}$ and to avoid metformin when serum creatinine is greater than $1.7 \mathrm{mg} / \mathrm{dL}$ or eGFR is below $30 \mathrm{~mL} / \mathrm{min} / 1.73$ $\mathrm{m}^{2}$ [20]. In our patient, metformin may have been commenced when eGFR was greater than $30 \mathrm{~mL} / \mathrm{min} / 1.73 \mathrm{~m}^{2}$ but not adjusted to the increasing creatinine or falling eGFR.

Similarly metformin is contraindicated in liver failure, advanced heart failure or respiratory insufficiency, all of which are recognized risk factors for systemic hypoxia and lactic acidosis [21]. All these are recognized risk factors for metformin associated lactic acidosis [3]. In addition, severe acute illness with dehydration and co-therapy with NSAIDs, ACE inhibitors and antiretroviral treatment are also described as risk factors for MALA [5]. It is important to recognize that many patients with diabetes and ischaemic heart disease are on NSAIDs and ACE inhibitors along with metformin.

Early detection of MALA is important as well as difficult. Onset can be acute and often non-specific with general ill health, body ache, gastrointestinal symptoms [22] as in the case of our patient. Other features of metformin toxicity are hypotension, hypothermia, altered consciousness and hypoglycaemia [8]. High index of suspicion and appropriate evaluation of a patient on metformin presenting with these symptoms should be emphasized.

MALA is effectively treated by withdrawing metformin and haemodialysis which removes metformin from the circulation [23-26]. Therapeutic benefits of dichloroacetate, trihydroxy methyl aminomethane [26], as well as intravenous infusions of methylene blue [8] have been described in some cases. Frusemide (to increase metformin filtration rate), haemofiltration and continuous venovenous haemodiafiltration with bicarbonate replacement fluid are the other options described [22].

MALA in ICU setting has a $30 \%$ mortality rate [27]. However, these figures are better than what the $\mathrm{pH}$ and lactate levels would predict $[28,29]$. Although low $\mathrm{pH}$ and absence of renal failure [5] are described as poor prognostic factors, low $\mathrm{pH}$ and lactate levels are thought to be poor predictors of mortality in MALA [3]. Infact in some case series survivors have had higher lactate levels [30]. This is probably due to the fact that mitochondrial inhibition by metformin is easily reversed by haemodialysis irrespective of the $\mathrm{pH}$ or lactate level which are rapidly reversible [13]. Furthermore, reviewing recent literature Renda et al postulate that associated co-morbid risk factors are stronger predictors of mortality than the dose of metformin or degree of impairment of its elimination, in metformin intoxication [5]. Whether this applies same to inadvertent overdosing as in the case of our patient, remains uncertain.

\section{Conclusion}

Lactic acidosis is a rare complication of metformin therapy and its therapeutic benefits far outweigh the remote risk of lactic acidosis. However this case report highlights the importance of recognizing risk factors for metformin associated lactic acidosis and monitoring of renal functions and modifying the dose in high risk patients. With the rising prevalence of diabetes and increasing use of metformin a rise in this rare adverse effect can be anticipated. Mainstay of treatment includes supportive care, haemodialysis and withdrawal of metformin. A low $\mathrm{pH}$ or high lactate levels should not discourage active management as they are poor predictors of survival compared to lactic acidosis of other etiologies. 


\section{Declarations}

\section{Ethics approval}

Not applicable

\section{Consent to participate}

Informed written consent was obtained from the patient for use of his medical information in compiling the manuscript.

\section{Consent for publication}

Patient gave written informed consent to publish the clinical details without breaching confidentiality.

\section{Availability of data and material}

Not applicable. All data used for the case report were from patients past medical records and investigation findings during hospital stay and carry the patient's identity. Authors do not wish to share that information in public to ensure confidentiality and since relevant information are noted in this report.

\section{Competing interests}

Nothing to declare

\section{Funding}

None

\section{Authors' contributions}

HAD collected data, reviewed literature and compiled the manuscript. ESW and PK critically reviewed the report.

\section{Acknowledgement}

Authors wish to acknowledge the staff of Diabetes Research Unit for assistance in data collection and patient and family for kind cooperation in provision of information.

\section{References}

1. Inzucchi SE, Bergenstal RM, Buse JB, Diamant M, Ferrannini E, et al. (2012) Management of hyperglycemia in type 2 diabetes: a patientcentered approach: position statement of the American Diabetes Association (ADA) and the European Association for the Study of Diabetes (EASD). Diabetes Care 35: 1364-1379.

2. Kruger DF, Boucher JL, Banerji MA (2011) Utilizing current diagnostic criteria and treatment algorithms for managing type 2 diabetes mellitus. Postgrad Med 123: 54-62.

3. Timbrell S, Wilbourn G, Harper J, Liddle A (2012) Lactic acidosis secondary to metformin overdose: a case report. J Med Case Rep 6: 230.

4. Scheen AJ (1996) Clinical pharmacokinetics of metformin. Clin Pharmacokinet 30: 359-371.

5. Renda F, Mura P, Finco G, Ferrazin F, Pani L, et al. (2013) Metforminassociated lactic acidosis requiring hospitalization. A national 10 year survey and a systematic literature review. Eur Rev Med Pharmacol Sci 17: 45-49.

6. Marchesini G, Brizi M, Bianchi G, Tomassetti S, Zoli M, et al. (2001) Metformin in non-alcoholic steatohepatitis. Lancet 358: 893-894.

7. UK Prospective Diabetes Study (UKPDS) Group (1998) Effect of intensive blood-glucose control with metformin on complications in overweight patients with type 2 diabetes (UKPDS 34). Lancet 352: 854-865.
8. Plumb B, Parker A, Wong P (2013) Feeling blue with metforminassociated lactic acidosis. BMJ Case Rep pii: bcr2013008855.

9. Bailey CJ, Turner RC (1996) Metformin. N Engl J Med 334: 574-579.

10. Salpeter SR, Greyber E, Pasternak G, Salpeter E (2010) Risk of fatal and nonfatal lactic acidosis with metformin use in type 2 diabetes mellitus. Cochrane Database Syst Rev 2002: CD002967.

11. van Berlo-van de Laar IR, Vermeij CG, Doorenbos CJ (2011) Metformin associated lactic acidosis: incidence and clinical correlation with metformin serum concentration measurements. J Clin Pharm Ther 36: 376-82.

12. Kwong SC, Brubacher J (1998) Phenformin and lactic acidosis: a case report and review. J Emerg Med 16: 881-886.

13. Protti A, Russo R, Tagliabue P, Vecchio S, Singer M, et al. (2010) Oxygen consumption is depressed in patients with lactic acidosis due to biguanide intoxication. Crit Care 14: R22.

14. Davis BJ, Xie Z, Viollet B, Zou MH, (2006) Activation of the AMPactivated kinase by antidiabetes drug metformin stimulates nitric oxide synthesis in vivo by promoting the association of heat shock protein 90 and endothelial nitric oxide synthase. Diabetes 55: 496-505.

15. Kastanek L (2002) Using anakinra for adult rheumatoid arthritis. Nurse Pract 27: 62-65.

16. Lipska KJ, Bailey CJ, Inzucchi SE (2011) Use of metformin in the setting of mild-to-moderate renal insufficiency. Diabetes Care. 34: 1431-1437.

17. KDOQI (2007) KDOQI Clinical Practice Guidelines and Clinical Practice Recommendations for Diabetes and Chronic Kidney Disease. Am J Kidney Dis 49(2 Suppl 2): S12-154.

18. Nathan DM, Buse JB, Davidson MB, Ferrannini E, Holman RR, et al. (2009) Medical management of hyperglycemia in type 2 diabetes: a consensus algorithm for the initiation and adjustment of therapy: a consensus statement of the American Diabetes Association and the European Association for the Study of Diabetes. Diabetes Care 32: 193-203.

19. Bhattacharyya OK, Estey EA, Cheng AY (2009) Update on the Canadian Diabetes Association 2008 clinical practice guidelines. Can Fam Physician 55: 39-43.

20. National Institute for Health and Clinical Excellence (2010) The Management of Type 2 Diabetes: 2010 NICE Guidelines [Internet]. London, UK, National Institute for Health and Clinical Excellence, 2010.

21. Scheen AJ, Paquot N (2013) Metformin revisited: a critical review of the benefit-risk balance in at-risk patients with type 2 diabetes. Diabetes Metab. 39:179-190.

22. Baró-Serra A, Guasch-Aragay B, Martín-Alemany N, Sirvent JM, VallèsPrats M (2012) The importance of early haemodiafiltration in the treatment of lactic acidosis associated with the administration of metformin. Nefrologia 32: 664-669.

23. Gjedde S, Christiansen A, Pedersen SB, Rungby J (2003) Survival following a metformin overdose of $63 \mathrm{~g}$ : a case report. Pharmacol Toxicol 93: 98-99.

24. Heaney D, Majid A, Junor B (1997) Bicarbonate haemodialysis as a treatment of metformin overdose. Nephrol Dial Transplant 12: 1046-1047.

25. Teale KF, Devine A, Stewart H, Harper NJ (1998) The management of metformin overdose. Anaesthesia 53: 698-701.

26. Gehlbach BK, Schmidt GA (2004) Bench-to-bedside review: treating acid-base abnormalities in the intensive care unit - the role of buffers. Crit Care 8: 259-265.

27. Peters N, Jay N, Barraud D, Cravoisy A, Nace L, et al. (2008) Metforminassociated lactic acidosis in an intensive care unit. Crit Care 12: R149.

28. Nyirenda MJ, Sandeep T, Grant I, Price G, McKnight JA (2006) Severe acidosis in patients taking metformin--rapid reversal and survival despite high APACHE score. Diabet Med 23: 432-435.

29. Vecchio, S, Protti A (2011) Metformin-induced lactic acidosis: no one left behind. Crit Care. Crit Care 15: 107.

30. Lalau JD, Race JM (1999) Lactic acidosis in metformin-treated patients. Prognostic value of arterial lactate levels and plasma metformin concentrations. Drug Saf 20: 377-384. 